\title{
Light deprivation from birth and acetylcholinesterase activity in cortex of mature rats'
}

\section{ASSAR CORVIN and SEYMOUR AXELROD, State Univer- sity of New York at Buffalo, N.Y. 14214}

Specific acetylcholinesterase (AChE) activity was measured in visual and motor cortex of rats raised from birth to maturity in near total darkness and of control littermates reared in a light-dark cycling environment. Although systematic differences could be demonstrated between motor and visual areas, none was found between the deprived and the control groups.

Variations in environmental and experiential complexity have been shown to produce variations in both weight and total acetylcholinesterase (AChE) activity of cortical tissue of weaned rats reared under normal light-dark cycling conditions. An "enriched environment," as compared with an "impoverished" one, produces increases in both measures. The AChE activity increases less than the cortical weight, however, the net result being that the specific $\mathrm{AChE}$ activity (rate of hydrolysis of substrate per unit weight of tissue, or per unit weight of protein) is lower in the cortices of the enriched-environment animals than in those of impoverishedenvironment controls (Krech, Rosenzweig, \& Bennett, 1960; Bennett, Diamond, Krech, \& Rosenzweig, 1964).

It therefore seems reasonable to expect that the radical procedure of dark-rearing from birth might produce changes in specific $\mathrm{AChE}$ activity in rat visual cortex. Surprisingly, Maletta \& Timiras (1967) found no differences between the visuocortical specific $\mathrm{AChE}$ activity of nursling rats (21 days old) reared from birth in darkness, and that of control nurslings reared under light-dark cycling conditions. Since these investigators found significant decreases in the superior colliculi and lateral geniculates of their experimental animals, the sensitivity of their methods and the precision of their measurements were presumably adequate. Also of interest in Maletta and Timiras' results was the absence of systematically higher activity in sensorimotor than in visual cortex of the pups, while the brains of their mothers did exhibit such a gradient. Rosenzweig, Krech, \& Bennett (1958) and Bennett et al (1964) had earlier found specific AChE activity to be highest in motor, intermediate in somesthetic, and lowest in visual cortex. Thus it is possible that certain changes in cortical $\mathrm{AChE}$ activity may require longer periods of time than 21 days to manifest themselves. In the present study, we measured specific AChE activity in visual and motor cortex of rats reared from birth to maturity and kept until sacrifice (at age 102-242 days) either in darkness or in a light-dark cycling environment.

\section{METHODS}

Two female albino rats (Holtzman strain) pregnant by the same male, were placed in a light-proof ventilated cabinet 3 days before expected term. The litters were born on successive days. On the day that the second litter was born, the litters were divided, half of each litter remaining with its own mother, and the other halves being exchanged, at the same time being marked by ear punch for identification. One mother with half the total number of pups was placed in the lightproof cabinet. The other mother with the remaining pups was placed in a cabinet similar to the lightproof one except that its doors were fitted with transparent Plexiglas panels. Litter-splitting, as also weekly cleaning of the dark-reared Ss, was carried out rapidly in red light provided by a GE $25-\mathrm{W}$ photographic safety light dimmed down through a variable transformer to an intensity just allowing the procedures to be done after several minutes of dark adaptation. The same precautions were taken when, at age 25-26 days, the pups were removed from the mother, rapidly divided by sex and housed three to a cage.

Rats were removed from the cabinets in pairs (experimental, control) and brought to the biochemical laboratory in separate lightproof transport boxes. Both animals and boxes were marked only by code, which was not broken until all the analyses were complete.

AChE is present in both "soluble" and "insoluble" form, the latter fraction being considerably the greater in the rat brain. It is sometimes called "bound" $\mathrm{AChE}$, and sometimes thought of as "structural" AChE. Our interest being fundamentally in the more permanent changes that might be involved in the mechanisms underlying information input and processing in the CNS, it is this fraction only (as opposed to the total enzyme activity which is usually considered) that was examined in this investigation.

Sacrifice was by decapitation, under illumination provided by the dimmed red light. In a cold-room kept at a temperature between $2 \operatorname{deg} \mathrm{C}$ and $4 \mathrm{deg} \mathrm{C}$, the brain was immediately removed from the cranium, stripped of meninges and vessels, and the appropriate portions of cortex dissected out, using the method of Rosenzweig, Krech, Bennett, \& Diamond (1962). Tissues were homogenized in ice-cold phosphate buffer $(0.1 \mathrm{M}$, pH 7.8) using a Teflon pestle in glass-tube homogenizer, $0.15-\mathrm{mm}$ clearance at $5000 \mathrm{rpm}$, and repeatedly washed, with centrifugation at $30,000 \mathrm{~g}$ for $90 \mathrm{~min}$ in a refrigerated

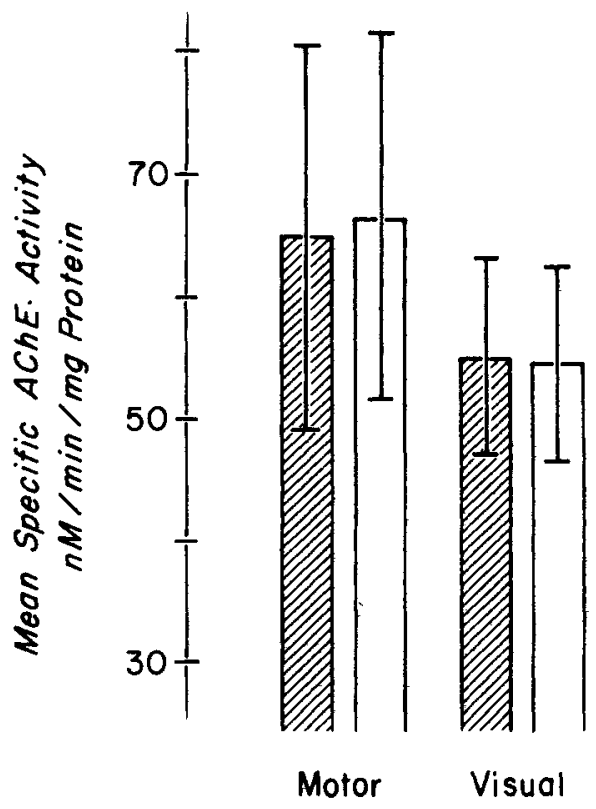

EIA DARK reared $\square$ LIGHT reared

Fig. 1. Mean specific AChE activity $\left(10^{-9} \mathrm{M}\right.$ substrate hydrolyzed/ $\mathrm{min} / \mathrm{mg}$ protein) in motor and visual cortex of the brains of rats raised under conditions of light deprivation, and normally raised controls. Vertical lines indicate one standard deviation above and one below the means. 
centrifuge, until no measurable activity remained in the supernatant. The residues were then treated with Crotalus atrox venom and incubated for $1 \mathrm{~h}$ at $37 \mathrm{deg} \mathrm{C}$ in a metabolic shaker in order to solubilize the insoluble fraction of $\mathrm{AChE}$. Finally, the supernatants obtained from this procedure by centrifugation as above were assayed for AChE activity and protein, using the methods of Ellman, Courtney, Andres, \& Featherstone (1961) and Ellman (1962). Results, in terms of specific activity, are expressed as nanomols substrate hydrolyzed per minute per milligram protein. Of a total of 11 pairs of animals, matched for genetic background, sex, and age, which were sacrificed over a 140-day period, four pairs were discarded (before code-breaking) because of apparatus failure or technician error in the laboratory. The ages at sacrifice of the seven remaining pairs were $102,110,123,130$, 172,214 , and 242 days.

\section{RESULTS}

Figure 1 shows the mean specific activities in the motor and visual areas of the two groups. The means were almost identical for the two groups. Within each group, mean specific activity was considerably greater in motor than in visual cortex. In four of the seven pairs, specific activity in the visual cortex was lower in light-deprived than in control animals; in three pairs, specific activity in the motor cortex was lower in light-deprived animals than in controls. In 11 of the 14 rats, specific activity was higher in motor than in visual cortex. A 2 (rearing conditions) by 2 (cortical areas) by 7 (pairs) variance analysis revealed that none of the first order interactions was significant, nor was the main effect of rearing condition. The effects of area and pair were both significant $(0.001<p<0.005$ in each test $)$.

\section{DISCUSSION}

So far as condition of rearing is concerned, the results indicate that under the stated conditions, light deprivation from birth well into maturity has no measurable effect upon $A(h l$ at ativity in visual and motor cortex of rats. This finding thus extends the observation of Maletta and Timiras (1967) on immature rats. As regards the areal gradient in mature rats, the present results are in agreement with those of both groups in Berkeley.

In considering the results, two comments at least are in order. First. light deprivation was not absolute, and there is the question of minimum stimulation required for enzyme induction, or possibly to "trigger" the process, which, once it has been initiated, might be maintained without further exogenous stimulation. Second, the extent of neuronal interconnections within cortical areas, and between these and subcortical centers, is such that the elimination of input from only one or two pathways such as those of the optic system may not be sufficient to lead to a measurable change of the nature under investigation.

It should, however, be noted that the nature of the measure used-specific activity-i.e., rate of hydrolysis/unit weight protein, is such that, should there actually be a decrease in enzyme activity with deprivation (as one might a priori expect) and should this be accompanied by a concomitant, more or less proportional decrease in protein, as measured by this assay, then one would obtain no apparent change in the specific activity, even though changes have taken place. That such changes might occur is suggested by reports from various workers [e.g., Gyllensten, Malmfors, \& Norrlin (1965, 1966); Globus \& Scheibel (1967); Maraini, Carta, Franguelli, \& Santori (1967); as well as the observation of Krech et al (1960) and Bennett et al (1965) cited in the introduction]. Thus, it might be necessary to measure specific AChE activity with reference to some tissue component other than protein as measured by the UV modification of the Biuret, in order to uncover such changes.

Matched pairs of experimental and control animals were always processed simultaneously. The significant effect of pairs found here is of interest in any consideration of laboratory techniques, instrument response, etc., and underlines the importance of running such controls.

\section{REFERENCES}

BENNETT, E. L., DIAMOND, M. C., KRECH, D., \& ROSENZWEIG, M. R. Chemical and anatomical plasticity of brain. Science, 1964, 146, 610-619.

ELLMAN, G. L., COURTNEY, K. D., ANDRES, V., \& FEATHERSTONE, R. M. A new and rapid colorimetric determination of acetylcholinesterase activity. Biochemical Pharmacology, 1961, 7, 88-95.

ELLMAN, G. L. The Biuret Reaction: Changes in the ultraviolet absorption spectra and its application to the determination of peptide bonds. Analytical Biochemistry, 1962, 3, 40-48.

GLOBUS, A., \& SCHEIBEL, A. B. The effect of visual deprivation on cortical neurons: A Golgi study. Experimental Neurology, 1967, 19, 331-345.

GYLLENSTEN, L., MALMFORS, T., \& NORRLIN, M. Effect of visual deprivation on the optic centers of growing and adult mice. Journal of Comparative Neurology, 1965, 124, 149-160.

GYLLENSTEN, L., MALMFORS, T., \& NORRLIN, M. Growth alteration in the auditory cortex of visually deprived mice. Journal of Comparative Neurology, 1966, 126, 463-470.

KRECH, D., ROSENZWEIG, M. R., \& BENNETT, E. L. Effects of environmental complexity and training on brain chemistry. Journal of Comparative \& Physiological Psychology, 1960, 53, 509-519.

MALETTA, G. J., \& TIMIRAS, P. Acetylcholinesterase activity in optic structures after complete light deprivation from birth. Experimental Neurology, 1967, 19, 513-518.

MARAINI, G., CARTA, F., FRANGUELLI, R., \& SANTORI, M. Effect of monocular light deprivation on leucine uptake in the retina and the optic centers of the newborn rat. Experimental Eye Research, 1967,6, 299-302.

ROSENZWEIG, M. R., KRECH, D., \& BENNETT, E. L. Brain chemistry and adaptive behavior. In H. F. Harlow and C. N. Woolsey (Eds.), Biological and biochemical bases of behavior. Madison: University of Wisconsin Press, 1958. Pp. 367-400.

ROSENZWEIG, M. R., KRECH, D., BENNETT, E. L., \& DIAMOND, M. C. Effects of environmental complexity and training on brain chemistry and anatomy. Journal of Comparative \& Physiological Psychology, 1962, 55, 429-437.

NOTE

1. This investigation was supported in part by the Buswell Foundation, SUNYaB, (A.C.) and by a Public Health Service Research Scientist Development Award (K3-MH-5787) from the National Institute of Mental Health (S.A.). The authors wish to thank Helen Remington, Frank Alabiso, and Morris Powazek for technical assistance.

\section{ERRATUM}

MARTIN, JOAN C. Sex differences in the activity wheel as a function of fetal age at irradiation. Psychonomic Science, $1968,13(5), 249-250$.-On page 249 the sentence beginning linè 41 should read "At 60 days of age there remained five males and five females in the 17 day $/ 200 \mathrm{R}$ group, 12 males and four females in the 19 day/200 $\mathrm{R}$ group, 10 males and four females in the $21 \mathrm{day} / 200 \mathrm{R}$ group, and six males and four females in the 19 day/0 R group." 